\title{
Article
}

\section{Coaching Games: Comparisons and Contrasts}

Price, Amy, Collins, David John, Stoszkowski, John Robert and Pill, Shane

Available at http://clok.uclan.ac.uk/26071/

Price, Amy, Collins, David John ORCID: 0000-0002-7601-0454, Stoszkowski, John Robert ORCID: 0000-0002-1968-5770 and Pill, Shane (2019) Coaching Games: Comparisons and Contrasts. International Sport Coaching Journal, 6 (1). pp. 126-131. ISSN 2328-918X

It is advisable to refer to the publisher's version if you intend to cite from the work. http://dx.doi.org/10.1123/iscj.2018-0015

For more information about UCLan's research in this area go to http://www.uclan.ac.uk/researchgroups/ and search for < name of research Group>.

For information about Research generally at UCLan please go to http://www.uclan.ac.uk/research/

All outputs in CLoK are protected by Intellectual Property Rights law, including Copyright law. Copyright, IPR and Moral Rights for the works on this site are retained by the individual authors and/or other copyright owners. Terms and conditions for use of this material are defined in the policies page.

\section{CLoK}

Central Lancashire online Knowledge www.clok.uclan.ac.uk

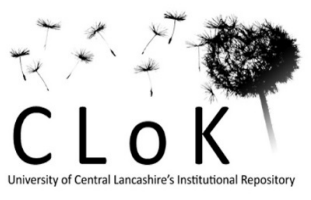


Running Head: COACHING GAMES: COMPARISONS AND CONTRASTS

Coaching Games: Comparisons and Contrasts

Amy Price*, Dave Collins, John Stoszkowski and Shane Pill

*Corresponding author. Amy.Price@TheFA.com

Date of revised submission: $19^{\text {th }}$ July 2018

This is an Accepted Manuscript of an article published by Human Kinetics in the International Sport Coaching Journal, available online:

https://journals.humankinetics.com/doi/abs/10.1123/iscj.2018-0015 


\begin{abstract}
A key feature of any coach's role is to decide on the most appropriate approach to develop player learning and performance at any given time. When coaching games, these decisions are even more challenging due to the interactive nature of games themselves and, in team games, this interactivity is heightened. Therefore, proponents of various approaches to coaching games could do well to demonstrate how different approaches may compliment rather than oppose each other, to avoid a one-size-fits-all process of coaching. In this insights paper, we summarize some of the fundamental approaches used for coaching games, whilst clarifying and contrasting their theoretical and practical differences. In doing so, we propose that there is a space in the coach's toolbox for a games approach that hones the metacognitive skills of players. We also suggest reasons why coaches might use metacognitive game design as a tool to develop players' deep understanding of game play to support player learning and performance. Keywords: deep understanding; digital video game design; meta-cognition; pedagogy
\end{abstract}




\section{Introduction}

Coaching games players is a particularly challenging process given the dynamic and complex nature of game play where interaction between players, skills, strategies, space and rules (to name but a few) influence how individuals and the team respond to any given situation (Grehaigne \& Godbout, 2014). Considering these complex and interactive variables, we would suggest that there is not one method (and nor should there be) amongst current espoused coaching tools that can meet all the needs of games players in the process of self and team development. Using Mosston and Ashworth's (2008, p.5) metaphor of tools as "invaluable to reaching the overall intended purpose," we take the outlook that coaching games requires purposeful adoption of a blended tool kit in order to find appropriate and effective context-specific solutions that enhance player learning and performance. In this paper, the term "approach" refers to the range of potential tools available for a coach to use. We understand that a tool becomes a tool (rather than a method) when coaches are aware of what it seeks to do, and how to use its principles appropriately. When discussing the notion of games, we refer to Almond's (1986) categorization of games that share similar tactical principles (net/wall, striking/fielding, target and invasion) because it summarizes the broad range of game types that occur in coaching.

Therefore, reflecting consideration of Mosston and Ashworth's (2008) metaphor of tools as a means to achieving an outcome, this paper sets out the coaching conundrum of selecting which approaches to use for developing games players, and why (Abraham \& Collins, 2011). Importantly, we provide critical consideration of conceptual, theoretical and practical characteristics inherent to three contrasting coaching approaches; Directed Approach (DA), Constraints-led Approach (CLA) and 
Coaching Games: Comparisons and Contrasts

Game Centered Approach (GCA) (cf. Metzler, 2011) before introducing a Metacognitive Approach (MA) via "Digital Video Games" (DVG) (Price, Collins, Stoszkowski, \& Pill, 2017) as a necessary addition to games coaching toolbox.

\section{The Conundrum of Coaching}

Dating back to the early sports coaching literature of Wade (1967), Wein (1973) and Worthington (1974), practitioners have utilized a range of approaches to develop player learning and performance in sport. It is logical to claim that there is no one "best way" to develop games players and there is an argument that the decision of "what" and "how" to support player learning is a matter of Professional Judgment and Decision Making (PJDM: Abraham \& Collins, 2011), dependent upon what is needed, for whom, and in what context (Abraham \& Collins, 2011). As a key focus of this paper, and one of the difficulties with this decision-making process for neophyte coaches, is the need to understand "why" a particular approach should be used over others so that the players' needs remain at the heart of coaching practice.

Unfortunately, however, literature pertaining to practice structures and coach behaviors in games often evidences evangelical "pushes" toward one particular approach (Ford, Yates, \& Williams, 2010; Harvey, Cushion, \& Massa-Gonzalez, 2010), as opposed to outlining critical choices, grounded in context specific frameworks of pedagogy, motor behavior and/or social and cognitive psychology (Cushion, Ford, \& Williams, 2012). For example, a historically common youth soccer training session begins with "training forms" (drills) and ends with "playing forms" (games), with explicit coach feedback a dominant behavior (e.g., using "stop standstill”) to support learning (O’Connor, Larkin, \& Williams, 2018). Furthermore, within training forms, the coach typically uses demonstration followed with verbal instruction in the quest to perfect execution of a technique (Williams \& Hodges, 2005), which is vastly different 
to engaging the player in a perception discovery process (Masters, 1992) to facilitate the process of skill execution. As such, with so many decisions for coaches when pursuing their goal of impacting players' learning and performance, the coaching conundrum is one of determining what is needed, for whom, in what context and why (Abraham \& Collins, 2011).

\section{Coaching Games}

\section{Gameplay - the additional challenge for coaches}

The uniqueness of coaching games presents an additional layer of complexity when deciding how to impact player learning, primarily due to games being open and complex systems that involve constant re-organization between players. Organization in an open system may be influenced by constraints (Newell, 1986) designed to achieve a desired outcome (Renshaw et al., 2016), or experiencing progressively (tactically) complex (Bunker, Thorpe, \& Almond, 1986) game forms to guide the process of organization (Bruner, 1960). Compared to a closed or predictable system, open systems in the case of games provide infinite opportunities for player-decision making under pressurized playing conditions (Masters, 2000). The essence of gameplay is to outwit your opponent through a process of puzzle solving (Almond, 2015), a term used to contextualize how problems emerge within an open system. The solutions (techniques, skills, tactics and strategies) that players use in these open systems can be considered as probabilities but cannot be pre-determined by the coach (Storey \& Butler, 2013). Underpinning these solutions is the internal logic of the game itself (Grehaigne, Godbout, \& Bothier, 1999; Grehaigne, Richard, \& Griffin, 2005). In defining the internal logic of any game category, Grehaigne, et al. (p. 8) explain that central to the notion of problem solving in games is interaction between "opposition to opponents, cooperation with partners, attack on the adverse camp, and defence of one's own camp." 
Considering the internal logic of games, the most effective players resolve problems in-action and with intent to outwit the opponent, driven by an understanding of how the game is designed (Almond, 1986).

\section{Games coaching toolbox - is there a space for a different tool?}

Unsurprisingly, there are a wide range of tools that can support players' in their endeavor to outwit the opponent. The epistemological differences in how skill is learned for net/wall, striking/fielding, target and invasion games, and thus performed or transferred in the context of competition are contrasted in Table 1.

As discussed earlier, the difficulty for coaches lies in discerning between each approach. For the purposes of this paper, we have intentionally selected four contrasting approaches for developing games players. All four approaches can be considered alongside the notion of outwitting the opposition, the essence of any game (Almond, 2015), and the underpinning of all problem-solving activities in games. With this view, we recognize a space in the coaching toolbox for a tool that supports players' metacognitive game skills (i.e., the "know-how-to-learn" dimensions of gameplay; Price, Collins, Stoszkowski, \& Pill, 2017, p. 2). Price et al. (2017) provide theory and practice examples of a MA, seeking to translate and transfer Gee's $(2007 ; 2013)$ “Good Digital Game Design” features (see Gee, 2013 for a detailed summary) into a sport coaching and teaching tool, known as a "Digital Video Games Approach" (DVG) (see Table 2). Prior to DVG as a coaching tool, the coaching literature did not present a solution for coaches to primarily focus on developing their players' metacognitive skills, as explained and distinguished in comparison to other approaches in Price et al. (2017).

In short, DVG for sport coaching focuses on practices that help players to become good learners, not just good players, by developing players' knowledge about 
their understanding, as well as what they do to monitor and control their learning. Metacognitive game skills occur during game play itself and are classed as metacognitive (and not cognitive) "if they have a conscious impact" (Brown, 1984, p.215). In the case of games, impact is considered to be when a skill is intended to consciously outwit the opponent. Examples of metacognitive game skills that relate to all four games categories include (but are not limited to): planning and re-planning strategy, replying to a problem by setting opponent a problem, and identifying what information is needed (from the game or game players) and setting out to find it.

Importantly, the process of using metacognitive game skills involves the player(s) (or team) consciously thinking about when and why to combine knowledge of playing the game (e.g., knowledge of the strategic-tactical-skill-technical elements of the game, score line, time remaining, rules) with knowledge of the opponent and/or team mates (e.g., knowledge of players' strengths, weaknesses, behaviors and characteristics), in order to have an impact. Previous work in sports coaching that has tested knowledge structures in games includes the extensive work of McPherson and Thomas (1989) and Nevett and French (1997), in which high level performers show greater flexibility in their sport specific tactical knowledge, and are therefore more capable of planning for, and then adapting tactics.

This notion of being flexible with tactics is also prominent in the work of Grehagine et al. (1999) within a team sport context, although in their case, tactics are specifically contrasted to strategy. Notably, strategic knowledge is described by these authors as cognitive processes that are influenced by reflecting without time constraints (i.e., devising a game plan in advance). Building from this empirical and conceptual body of research in sport coaching, however, we would tentatively hypothesize that a MA can purposefully develop players' metacognitive game skills, to cultivate players 
flexible application of strategic, tactical, skill and technical knowledge, even under strong time constraints (e.g., during game play).

The principal objective for using a MA such as DVG is nested in the concept of “deep understanding” as a blanket learning principle (Gee, 2007; 2013). Although there have been various attempts to unravel the concept of understanding itself within game categories (e.g., Almond \& Ayres, 2013; Ayres \& Almond, 2014) to help coaches facilitate effective learning and assessment of players, a distinction in the present paper is to propose how metacognitive game design has the potential to improve players' deep understanding. We propose the notion of deep understanding for playing games (in comparison to understanding) is defined by adopting metacognitive game skills to outwit the opponent. In contrast to a player without deep understanding, who does not join together their thoughts about the game and the players playing the game, to consciously intend on outwitting the opponent.

\section{Using Digital Video Games for Deep Understanding}

It is important to highlight that none of Gee's work in digital game design makes explicit links to work on metacognition. Initial links between Gee's notion of deep understanding and metacognition, specifically Flavell's (1979) seminal work, was made by Price et al. (2017), who originally introduced DVG. Therefore, it is timely to explain the relevance of Flavell's (1979) work for games coaching. Writing from the perspective of education, Flavell (1979) proposes four classes of metacognition (knowledge, experience, goals and strategies), which Robinson (1983) later suggests act as a taxonomy for future research in this area. However, definitions of metacognition remain "fuzzy" (Perry, Lunder, \& Golder, 2018), despite recent empirical studies indicating positive effects on pupil outcomes for metacognitive strategies used in school, and across curriculum (Mannion \& Mercer, 2016). Cross- 
curricular evidence is significant given that sport and games operate within distinctly different boundaries to typical classroom subjects, such as math and science. Games as open and complex systems require players to use both declarative (know-about) and procedural knowledge (know-how) in dynamic contexts where no conditions are ever the same, it is therefore appropriate to focus on Flavell's (1979) definition of metacognitive knowledge. In this definition, metacognitive knowledge concerns; person (declarative knowledge; knowledge of people playing in the game), task (procedural knowledge; knowledge of playing the game) and strategy (conditional knowledge; combining procedural and declarative knowledge to outwit the opponent). This particular framework of person, task and strategy for metacognitive knowledge is relevant for playing games due to the strategic, tactical, skill and technical elements, which invariably occur within an open and complex system.

The following section is organized into three elements that explain deep understanding in the context of playing games. For each element we provide a principle relevant to learning in games (in the form of a player's thought process), and a suggestion in regard to game design (to support coaches with practical application). We finish with potential implications of the principle for player learning and performance. Information is arranged in such a way so as to distinguish conceptually and practically between understanding (cognitive) and deep understanding (metacognitive). Herein the key difference being deep understanding refers to a metacognitive awareness of when and why to use knowledge of the game, and knowledge of players playing the game, in order to outwit the opponent.

\section{Deliberate thinking and action (planning and re-planning strategy)}

Principle. "The plan is to use this strategy, though we might need to re-plan depending on what happens in the game." 
Game design. Designing a game that uses an overarching goal (mission), avoiding allusion to any kind of skill specific or tactic driven learning outcomes or processes has the potential to engage players in a method of strategic planning.

Effects for player learning and performance. Proposing a broad "mission" (Price et al., 2017 , p.7) rather than specific processes or outcomes creates opportunity for players to strategize by consciously selecting the appropriate tactics and skills and then deliberately practicing these strategies in order to get closer to achieving the mission. When designing a mission, the coach is encouraged to begin the mission with a verb that does not directly link to any kind of sport specific skill. For example, the mission is to unlock players from zones (invasion games), or the mission is to collect more points that your opponent (net/wall games), or the mission is to build new areas of the pitch (striking/fielding), or the mission is to stay on the green (target games) (for comprehensive examples of how coaches can design games that use missions, see Price et al., 2017, p 7-8). Given the dynamic complexities of physical games themselves (layers of actions designed to outwit opponents), players may need to alter their strategy in-action, and therefore change what tactics and skills they plan on using (deliberately practicing) in the game. Importantly, the coach will accept any strategies, tactics and skills decided on by the players, and appreciates that these choices will (and should) change.

In game play, players will. Think strategically and develop a capacity to adapt strategy based upon the state of the game, to achieve the game's mission, as opposed to practicing specific attributes of the game decided on by the coach.

Meta-level problem solving (replying to a problem by setting the opponent a problem) Principle. "This is how to solve the problem we face, and we're using this solution so that the game poses problem X to the opponent." 
Game design. Integrating a mechanism into game design to provide teaching for players should they decide. This will extend players' awareness of their own problem-solving capabilities, an awareness of other players' game capabilities, and an awareness of how the game design affords opportunities for teammates and/or opposition to find success. Effects for player learning \& performance. Applying the "4 C's" idea by "using the pause button" (Price et al., 2017, p. 8) in game design facilitates player led pauses for players to select from different types of support (e.g., cheat, change, clue, challenge). In effect, offering opportunities for players to use declarative knowledge to decide on new ways to interact with the game, and thus encourages development of procedural and conditional knowledge in game to re-think and re-plan (for comprehensive examples of how coaches can design games that use player led pauses, see Price et al., 2017, p. 7-8). Thus, by offering opportunities for players to decide what support they require, to solve a problem develops players' appreciation of interdependence between teammates, opponents and the game design. Importantly, players seek to make conscious decisions for action based upon the game mechanisms and other players' actions in order to find appropriate solutions to outwit the opponent. The focus here is to problem solve by thinking like a player (the opponent is doing X, so I/we need to do $\mathrm{Y}$ ), and to problem set by thinking like a game designer (if I/we do Y, then the opponent will find $\mathrm{Z}$ difficult).

In game play, players will. Identify when, how and with what they require support with a view to set a problem for the opponent, rather than the coach initiating (and leading) the support process based upon observations of game play.

Good learners and teachers (players identify what they need to find out, and set out to find it) 
Principle. "I've realized that we are finding X situation difficult in this game; I'm going to find new knowledge of the game to alter how I deal with this situation in the future." Game design. Facilitating opportunities in the game for players to earn "super powers" (Price et al., 2017, p. 9) so that players become more effective in short periods will provide further sources of knowledge for players to evaluate how to deal with new or difficult circumstances.

Effects for player learning \& performance. Players can see that the game has the potential to alter its design depending on how super powers can be earned and then used. This encourages players to deliberately seek out and persist in locating specific pieces of information believed to be required for a given situation (for comprehensive examples of how coaches can design games that use super powers, see Price et al., 2017, p. 7-8). Through experiencing a co-designed approach to learning, players identify what they can do, and what they can't do, and are encouraged to recognize their (individual or team) progress in the game. Of particular relevance is the notion that players are not dependent on a significant other (i.e., coach) to control the challenge of the game; instead they are able to use the game's design to pick out "nuggets" of information that will help them to progress. Importantly, super powers that are carefully woven into game design develop players' metacognitive evaluation of their performance in the game, and thus players act as their own teachers.

In game play, players will. Self-direct their own learning by being "deliberate learners," who are pro-active in teaching themselves in any game context, rather than relying on the coach to simplify or deconstruct the game form when a situation is new or difficult.

We have set out some items for a MA via DVG that may contribute towards the makeup of a coach's toolbox, should the coach be aiming to enhance players' deep understanding of the game. 
Coaching Games: Comparisons and Contrasts

\section{Conclusion}

We hope to have summarized some of the fundamental approaches used for coaching games, whilst clarifying and contrasting their theoretical and practical differences. It is our intention that clarifying the processes for each approach will support coaches in their endeavor to effectively develop players and ultimately help coaches to make and justify professional judgments on the use of specific tools in specific contexts (Abraham \& Collins, 2011). With this in mind, we propose that there is a space in the coach's toolbox for a method that hones the metacognitive skills of players, which are important for games players because the process of consciously outwitting an opponent requires interacting knowledge of not just the game but also of the people playing it. Using the theoretical work of Flavell (1979) and conceptual work of Gee $(2007 ; 2013)$ and Price et al. (2017) we propose three metacognitive game skills, and their effects on player learning and performance. These skills occur during game play, and consist of planning and re-planning strategy, replying to a problem by setting the opponent a problem, and identifying what they need to find out and setting out to find it. Of course, it should be noted that these are currently propositions, and there is imminent need for ongoing empirical investigation.

In concluding our overview of contrasting approaches for coaching games, we should make clear that we are not suggesting that a MA is superior to any other. Instead, we have identified a need for the processes of contrasting approaches to be clarified, and in doing so, detailed a tool that coaches might deploy should they wish to enhance their players' metacognitive skills and knowledge for games. In summary, we refer to Abraham and Collins' (2011) work on PJDM to empower coaches to make evidenceinformed decisions (rather than evangelical choices) and present the comparative insights to support coaches in their ongoing player development dilemmas. 


\section{References}

Abraham, A., \& Collins, D. (2011) Taking the next step: Ways forward for coaching science, Quest, 63(4), 366-384.

Almond, L. (1986). Games making. In . Thorpe, R., Bunker, D., \& Almond, L. (Eds.), In Rethinking Games Teaching (pp. 35-44). Loughborough: University of Technology Loughborough.

Almond, L. (2015). Rethinking teaching games for understanding. Ágora para la Educación Física y el Deporte, 17(1), 15-25.

Almond, L., \& Ayres, M. (2013). Taking the first steps: An exploration of the meaning of understanding in physical education. Physical Education Matters, 8(3), 6770.

Ayres, M., \& Almond, L. (2014). Understanding in the teaching of games and its significance for physical education. Physical Education Matters 9(1), 15-17.

Brown, G. (1984). Metacognition: New insights into old problems? British Journal of Educational Studies, 32(3), 213-219.

Bruner, J. S. (1960). The process of education. Cambridge, MA: Harvard University Press.

Bunker, D. J., \& Thorpe, R. D. (1982). A model for the teaching of games in secondary schools. The Bulletin of Physical Education, 18(1), 9-14.

Cushion, C., Ford, P. R., \& Williams, M. (2012). Coach behaviours and practice structures in youth soccer: Implications for talent development, Journal of Sports Sciences, 30(15), 1631-1641.

Flavell, J. H. (1979). Metacognition and cognitive monitoring. American Psychologist, 34(10), 906-911.

Ford, P. R., Yates, I., \& Williams, A. M. (2010). An analysis of practice activities and 
instructional behaviours used by youth soccer coaches during practice: Exploring the link between science and application. Journal of Sports Sciences, 28(5), 483-495.

Gee, J. P. (2007). Good video games and good learning (New literacies and digital epistemologies). New York, NY: Peter Lang Publishing, Inc.

Gee, J. P. (2013). Good video games and learning. New York, NY: Peter Lang Publishing Inc.

Grehaigne, J. F., Richard, J. F., \& Griffin, L. (2005). Teaching and learning team sports and games. New York, NY: RoutledgeFalmer.

Grehaigne, J. F., Godbout, P., \& Bouthier, D. (1999). The foundations of tactics and strategy in team sport. Journal of Teaching in Physical Education, 18(2), 159174.

Grehaigne, J.F., \& Godbout, P. (2014). Dynamic Systems Theory and Team Sport Coaching. Quest, 66(1), 96-116.

Harvey, S., Cushion, C., \& Massa-Gonzalez, A. N. (2010). Learning a new method: Teaching games for understanding in the coaches' eyes. Physical Education and Sport Pedagogy, 15(4), 361-382.

Mannion, J., \& Mercer, N. (2016). Learning to learn: Improving attainment, closing the gap at Key Stage 3. The Curriculum Journal, 27(2), 246-271.

Masters, R. S. W. (1992). Knowledge, nerves and know-how: The role of explicit versus implicit knowledge in the breakdown of a complex motor skill under pressure. British Journal of Psychology, 83, 343-358.

Masters, R. S. W. (2000). Theoretical aspects of implicit learning in sport. International Journal of Sport Psychology, 31, 530-541. 
McPherson, S., \& Thomas, J. (1989). Relation of knowledge and performance in boys' tennis: Age and expertise. Journal of Experimental Child Psychology, 48, 190211.

Metzler, M. W. (2011). Instructional models for physical education (3rd ed.). Scottsdale, AZ: Holcomb Hathaway.

Mosston, M., \& Ashworth, S. (2008). Teaching physical education: First online edition. Jupiter, FL: The Spectrum Institute for Teaching and Learning.

Nevett, M., \& French, K. (1997). The development of sport-specific planning, rehearsal, and updating of plans during defensive youth baseball game performance. Research Quarterly for Exercise and Sport, 68(3), 203-214.

Newell, K. M. (1986). Constraints on the development of coordination. In M. G. Wade \& H. T. A. Whiting (Eds.) Motor development in children: Aspects of coordination and control (pp. 341-360). Dordrecht: Martinus Nijhoff.

O’Connor, D., Larkin, P., \& Williams, M. A. (2018). Observations of youth football training: How do coaches structure training sessions for player development? Journal of Sports Sciences, 36(1), 39-47.

Perry, J., Lundie, D., \& Golder, G. (2018). Metacognition in schools: What does the literature suggest about the effectiveness of teaching metacognition in schools? Educational Review. doi: 10.1080/00131911.2018.1441127

Price, A., Collins, D., Stoszkowski, J., \& Pill, S. (2017). Learning to play soccer: Lessons on meta-cognition from video game design. Quest. doi: $10.1080 / 00336297.2017 .1386574$

Renshaw, I., Araujo, D., Button, C., Chow, J. Y., Davids, K., \& Moy, B. (2016). Why the constraints-led approach is not teaching games for understanding: A 
clarification. Physical Education and Sport Pedagogy, 21, 459-480. doi:10.1080/17408989.2015.1095870

Robinson, E. (1983). Metacognitive development. In S. Meadows (ed.), Developing thinking (pp.106 - 141). London: Methuen.

Storey, B., \& Butler, J. (2013). Complexity thinking in PE: Game centred approaches, games as complex adaptive systems, and ecological values. Physical Education and Sport Pedagogy, 18(2), 133-149.

Thorpe, R. D., Bunker, D. J., \& Almond, L. (1986). Rethinking games teaching. Loughborough: Loughborough University of Technology.

Wade, A. (1967). The F.A. guide to training and coaching. London: Heinemann.

Wein, H. (1973). The Science of Hockey. 1st ed. London: Pelham.

Williams, A. M., \& Hodges, N. J. (2005). Practice, instruction and skill acquisition in soccer: Challenging tradition. Journal of Sports Sciences, 23(6), 637-650.

Worthington, E. (1974). Teaching soccer skill. 1st ed. London: Lepus Books. 
Table 1

Approaches for Coaching Games and their Levels of Epistemological Understanding

\begin{tabular}{|c|c|c|c|}
\hline Approach & Knowledge & Assertions & In Practice \\
\hline $\begin{array}{l}\text { Directed } \\
\text { Approach } \\
\text { (DA) }\end{array}$ & $\begin{array}{l}\text { Shaping } \\
\text { action } \\
\text { (know-about) }\end{array}$ & $\begin{array}{l}\text { Constant conditions with } \\
\text { few player decision-making } \\
\text { opportunities result in better } \\
\text { technical performance, } \\
\text { compared to practices with } \\
\text { greater player decision- } \\
\text { making opportunities which } \\
\text { result in greater tactical } \\
\text { learning retention and } \\
\text { transfer (Williams \& } \\
\text { Hodges, 2005). } \\
\text { Explicit direction and } \\
\text { feedback in reference to an } \\
\text { optimal technical model of } \\
\text { performance result in better } \\
\text { technical performance } \\
\text { during constant conditions, } \\
\text { compared to implicit } \\
\text { instruction which supports } \\
\text { skill from breaking down } \\
\text { under stress (Masters, } \\
\text { 2000). }\end{array}$ & $\begin{array}{l}\text { Practice is decontextualized } \\
\text { from the game, or modified } \\
\text { game forms (limited } \\
\text { variations in conditions). } \\
\text { Focus on repetition of } \\
\text { technique, rather than skill } \\
\text { (action is not attached to a } \\
\text { tactical problem). } \\
\text { Linear approach to learning, } \\
\text { where complexity of the game } \\
\text { is removed. } \\
\text { Technical model to inform } \\
\text { process of action, rather than } \\
\text { discovery of process to } \\
\text { achieve outcome. }\end{array}$ \\
\hline
\end{tabular}




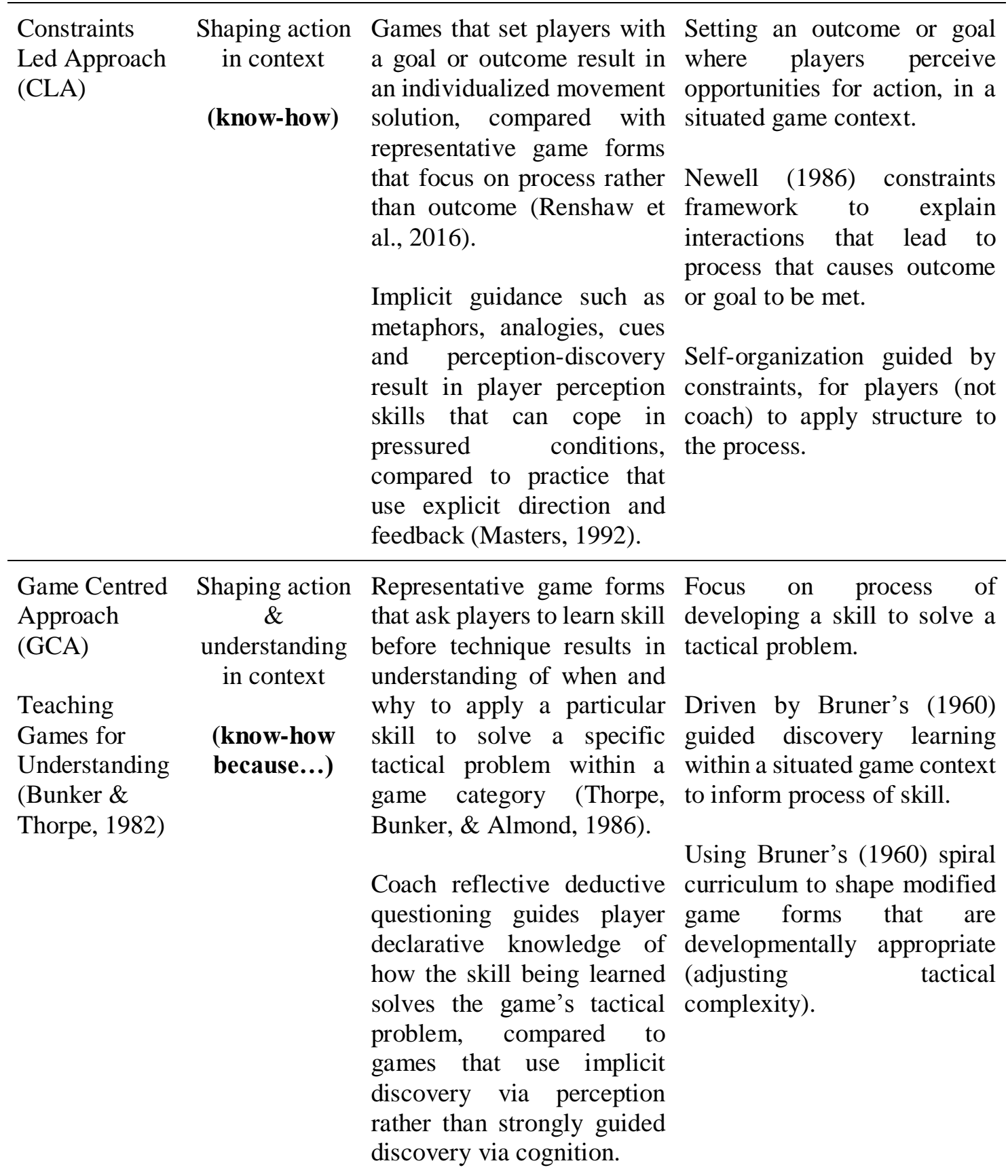




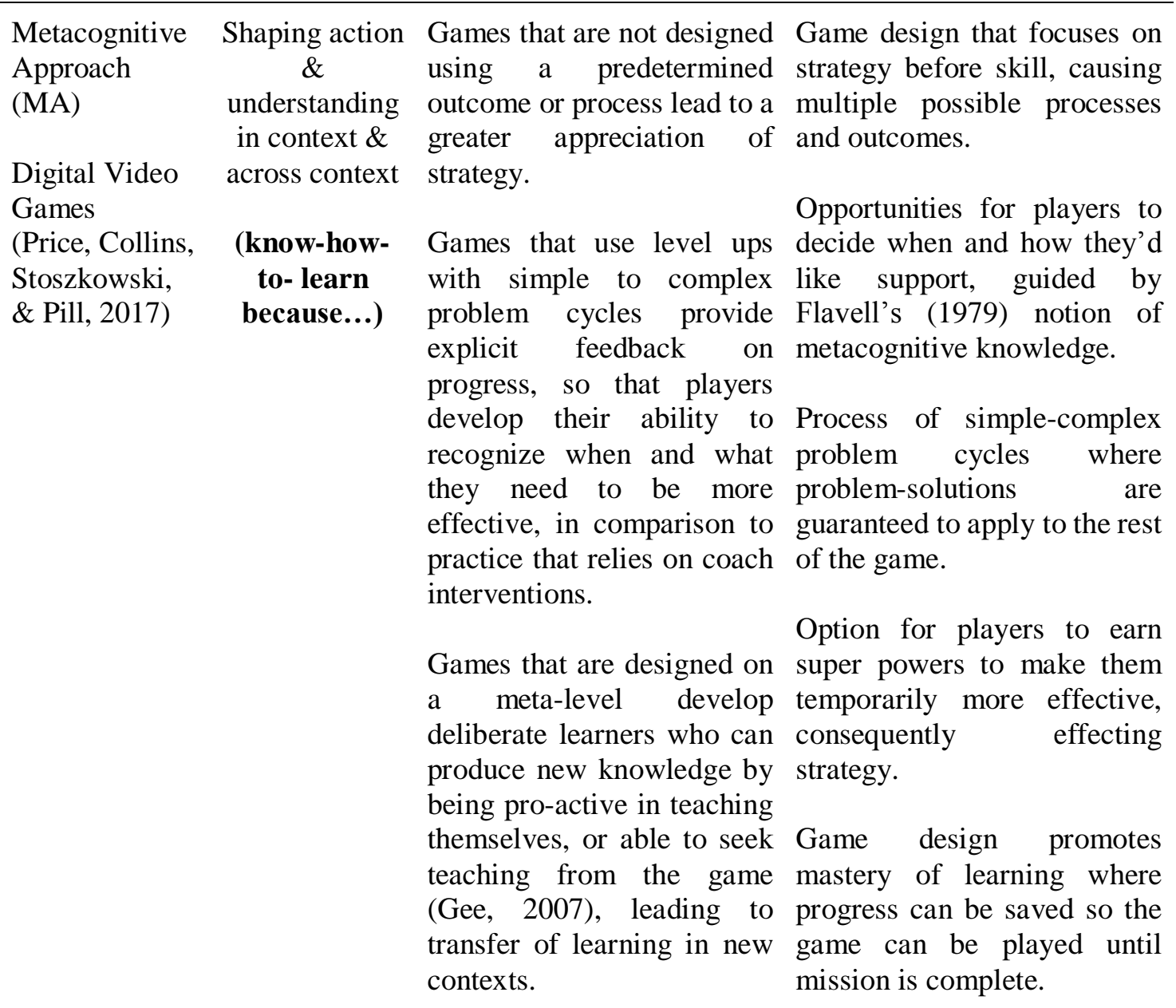

Approach

Digital Video

Games

(Price, Collins

Stoszkowski,

\& Pill, 2017)

\section{to- learn}

Table 2

$\begin{array}{ll}\text { Principle } & \text { Characteristics }\end{array}$

What's the Mission?

- No technical/skill/tactical focus

- Emphasis on players' strategizing and re-strategizing

- Coach mindset shifts from "this is what we will we be learning today" to "this is today's mission"

Using the Pause Button

- Integrating varying degrees of support for players via the "4 C's" - Cheat, Change, Clue, Challenge

- Players decide when, how and with what they'd like support via the "4 C's"

- Coach mindset shifts from "how can I help or challenge the players" to "how are players responding to the mission" 
Level-Up!

Earning a Super Power

- Complexity (variations of time and space) moves from simple to complex levels, where players can be on different levels within the same game

- Initial assessment of players occurs via their metacognitive skills

- Coach mindset shifts from "what's my next progression for this practice" to "who's likely to level-up next"?

- Providing players with the opportunity to be more effective for a short period of time

- Players decide when and why they need the power, and how best to use it

- Coach mindset shifts from "how do I adjust the task to meet the ability of all players" to "what super power might be helpful for players to earn"

Saving Progress

- Individual players/teams end and re-start the game at different points and therefore with a challenge point that is relevant

- Players are inclined to take risks in game play because the game won't allow for regression

- Coach mindset shifts from "we need to cover all of this technical or tactical content" to "let's allow the players to spend time mastering this game"

Pedagogical principles for a Digital Video Games Approach 